\title{
LncRNA \& Wnt signaling in colorectal cancer
}

\author{
Zeeshan Javed ${ }^{1}$, Khushbukhat Khan ${ }^{2}$, Haleema Sadia ${ }^{3}$, Shahid Raza ${ }^{4}$, Bahare Salehi ${ }^{5,6^{*}}$, Javad Sharifi-Rad ${ }^{7^{*}}$ (1) \\ and William C. Cho ${ }^{8^{*}}$
}

\begin{abstract}
The outlook for new therapeutic approaches is pivotal to ameliorate the deterioration caused by the abrogated Wnt signaling. Long non-coding RNAs (IncRNAs) are tiny molecules that have begun emerging as vital molecular manager for the regulation of various cellular processes at transcription and translation levels in the colorectal cancer (CRC). Targeting Wnt pathway with IncRNA seems a promising approach to eradicate CRC. However, little is known of their active role in commencing both apoptosis and proliferation in CRC. This article reviews the importance of these molecules in the pathogenesis of CRC and also emphasizes on the development of new therapeutic strategies to cope with the Wnt mediated CRC.
\end{abstract}

Keywords: Wnt signaling, Colorectal cancer, IncRNA, Therapeutics strategy

\section{Background}

Colorectal cancer (CRC) is the third most prevalent maligancy in the world. It has been estimated that there are 1.8 million cases of CRC reported globally and the figure will project to have an upsurge to 2.6 million in the next decade [1]. CRC incidence ranges from 6.5 per 100,000 in the middle east and Africa to 83.7 per 100,000 in Asia pacific. However, the incidence of CRC is highest among Asian countries with 737,000 cases reported each year [2]. The new therapeutic interventions is pivotal for disease management. Despite the advancement in the field of precision targeting of cancer with small molecules, the treatment of CRC is still bleak. Unavailability of validated molecular and phenotypic targets has greatly stalled the efficacious treatment of CRC. Monoclonal antibodies targeted against epidermal growth factor receptor $(E F G R)$ and vascular endothelial growth factor (VEGF)

\footnotetext{
*Correspondence: bahar.salehi007@gmail.com; javad.sharifirad@gmail.com; chocs@ha.org.hk

${ }^{5}$ Noncommunicable Diseases Research Center, Bam University of Medical Sciences, Bam, Iran

${ }^{7}$ Phytochemistry Research Center, Shahid Beheshti University of Medical Sciences, Tehran, Iran

${ }^{8}$ Department of Clinical Oncology, Queen Elizabeth Hospital, 30 Gascoigne Road, Hong Kong, China

Full list of author information is available at the end of the article
}

have gleaned some success. However, poor prognosis in advanced CRC has greatly hampered their effective use [3]. High-throughput technologies, e.g. next-generation sequencing have begun to scratch the surface of the mutations that drive intestinal epithelial cell transformation and carcinogenesis in the CRC. Mutations associated with de-regulated Wnt-signaling cascade entails severe proliferative characteristics in various subtypes of $\mathrm{CRC}$ and thus are the promoting factors in many forms of CRC [4]. So far, mutations of adenomatous polyposis coli $(A P C)$ have been enlisted as the primal genetic event that leads to tumorigenesis in the CRC [5]. Also, a series of mutation drivers that deregulate the machinery are involved in regulating cell growth, development and differentiation of CRC [6]. Oncogenic mutations in the Wnt pathway are a hallmark in CRC. More than $80 \%$ CRC tumors carry inactivating mutations in the regulatory component of $W n t$ pathway such as the APC. APC have been implemented to be a decisive factor in the malignant transformation of the CRC epithelial cells [7]. Long non-coding RNAs (lncRNA) are small molecules that have been implemented to orchestrate plethora of cellular processes. Involvement of $\operatorname{lncRNAs}$ in modulation of gene expression and regulation of signaling cascades has been a spotlight over the years [8]. LncRNAs are small molecules by size $>200 \mathrm{bp}$. Advances in the field original author(s) and the source, provide a link to the Creative Commons licence, and indicate if changes were made. The images or other third party material in this article are included in the article's Creative Commons licence, unless indicated otherwise in a credit line to the material. If material is not included in the article's Creative Commons licence and your intended use is not permitted by statutory regulation or exceeds the permitted use, you will need to obtain permission directly from the copyright holder. To view a copy of this licence, visit http://creativecommons.org/licenses/by/4.0/. The Creative Commons Public Domain Dedication waiver (http://creativeco mmons.org/publicdomain/zero/1.0/) applies to the data made available in this article, unless otherwise stated in a credit line to the data. 
of molecular biology have begun to unravel the mysteries of $l n c R N A s$ in various cancers. LncRNAs possess unique properties that separate them from the coding RNAs [9]. The majority of CRCs is driven by the oncogenic mutations in Wnt pathway [10]. Despite the influential role of $W n t$ mutations in the CRC, the role of $\operatorname{lncRNAs}$ in regulating the Wnt signaling cascade in CRC is still dreary [3]. Exploring $\operatorname{lncRNAs}$ as a therapeutic target for Wnt mediated abrasions in CRCs is a promising strategy. Here we give a brief review of lncRNAs involved in Wnt pathway that may be targeted in the CRC.

\section{Wnt signaling pathway in CRC}

Wnt pathway has been reported to orchestrate differentiation and development of metazoan via modulation of the key transcriptional framework [6]. Both canonical and non-canonical signaling of the Wnt Pathway contributes to the development and differentiation [11]. In case of canonical Wht signaling (also referred to as Wnt/ $\beta$-catenin signaling), the downstream processing is controlled by a squad of context-specific afferent ligands such as the frizzled $(f z d)$, phosphor tail of $L R P 5 / 6$ and disheveled protein $(D s h)$. Wnt/ $\beta$-catenin signaling cascade expression is strictly guided by $\beta$-catenin destruction complex consisting of $A P C$ (adenomatous polyposis coli), Axin2, casein kinase (CK1) and glycogen synthetase kinase $\beta($ GSK $\beta)[12,13]$. $\beta$-catenin destruction complex explicitly monitor degradation of $\beta$-catenin through proteasome-mediated destruction complex, comprising of protein E3 ubiquitin ligase (beta-transducin repeat containing E3 ubiquitin protein ligase) $\beta-T R C P$ [14]. The destruction complex phosphorylates the $\beta$-catenin at serine/threonine residues at the $\mathrm{N}$-terminus which facilitates ubiquitination by $\beta-T R C P$ for proteasome recruitment [13]. Presence or absence of $A P C$ is a defining factor in the working of the destruction of the complex. APC safeguards covalent modifications of $\beta$-catenin that ensure scaffolding and the assembly of the destruction complex [15]. However, the activation of Wnt signaling cascades by sequential ligands (Dsh, LRP5/6 and $F z d$ ) efficiently hampers ubiquitination by the destruction complex. Furthermore, these context specific ligands promote $\beta$-catenin to stabilize and interact with various transcription factors such as the (Tcell factor and lymphoid enhancer factor) TCF/LEF (T cell factor/lymphoid enhancer factor) family of transcription factors. Recruitment of transcription factors of target genes greatly enhances the Wnt pathway target gene expression [16].

\section{LncRNAs: the mediators and modulators of cancer}

The human genome is more intrusive as a vast portion of the genome is not transcribed into proteins. This noncoding genome was once referred to as junk DNA [17].
However, genome wide analysis approaches and high throughput technologies have begun to delineate the mysteries of the non-coding genome. LncRNAs which are comparatively larger than the microRNAs have started to emerge as a potent player in the cancer biology [18]. Noncoding RNAs share certain homologies with the coding genome, yet they have their own significant features that part them from the coding genome. Based on genomic peculiarities non-coding RNAs are divided into long non-coding RNAs (lncRNAs), long intergenic non-coding RNA (lincRNA), ultra-conserved regions (T-UCRs), enhancer RNA (eRNAs), circular RNA (c-RNAs), Promoter associated RNAs and several others [19]. Based on their functions $\ln c R N A s$ can act as (i) signal transducer; (ii) molecular decoy; (iii) molecular Sponge; (iv) CisTrans activator and; (v) chromatin remodeler [20].

Plethora of studies has shed light on the crucial role of lncRNAs in CRC. Wht signaling is a crucial mediator of cellular growth, proliferation, invasion and metastasis. The interaction between Wnt-signaling and lncRNAs seems to be promising approach to understand the complex nature of CRC, Here we explain the interplay between lncRNAs and Wnt-signaling on the basis of different functions (signal transducer, molecular decoy, molecular Sponge, Cis-Trans activator, and chromatin remodeler). We have attempted to explain how lncRNAs interplay with Wnt-signaling to trigger growth or apoptosis and how can IncRNAs be used as prognostic or diagnostic marker for early and rapid detection of CRC.

\section{Interplay between IncRNAs and Wnt-Signaling in CRC}

Molecules involved in Wht signaling directly or indirectly affect gene expression by acting as a transcription factor or modulating the expression of other transcription factors. Furthermore, several studies have demonstrated the involvement of $\operatorname{lncRNAs}$ in the regulation of the Wnt signaling cascade at both transcriptional and translational levels [21]. Wnt signaling is indispensable for a plethora of cellular processes which includes tumor proliferation, metastasis and stemness [22]. Wnt signaling orchestrates these cellular processes in CRC. In addition, Wnt signaling cascade plays a pivotal role in maturation, differentiation and development of the both normal and cancer stem cells $[22,23]$. LncRNA have begun to scratch the surface of the essential regulatory machinery involved CRC [24]. The interplay between lncRNA and Wnt signaling cascade is brimming with opportunities to delineate the role of these micro managers in development, differentiation and metastasis of CRC (Table 1). LncRNAs possess many advantages as majority of lncRNAs associated with Wnt signaling in CRC shed light on prognosis [25]. Therefore, they may be used as powerful diagnostic approach for the early detection of the 
CRC. The modulation of wnt signaling cascade through lncRNAs is illustrated in Fig. 1. Recent study has demonstrated the role of PCA3 a lncRNA in prostate cancer. Expression analysis in conjunction with disease progression indicated that IncRNA could be implemented as tissue specific cancer biomarker for prostate cancer [26]. In addition to this expression of a specific lncRNA is tissue specific and often is under the influence of specific genes, consequently lncRNA can be explored as biomarker as it has been exemplified using the CCAT-1 expression in response to BRD4 in clinical trials. Since many lncRNAs explored so far have genetic predisposition towards tumor. Their interaction with DNA or RNA can predict the out-come of disease and thus can be implemented as biomarker for SNPs mediated tumor anomalies [27]. LncRNAs regulate Wnt-signaling cascade thus, they can evince to be valuable therapeutic option for the treatment of various cancers. In addition to this role of PVT1 in fine tuning the expression of the c-MYC protein can be utilized as source for therapeutic interventions [28]. Lnc34a is another IncRNA that can be perceived as a therapeutic tool against CRC as it has been involved in the regulation of CRC stem cells. Furthermore, lnc34a ameliorates the aggravated cancer stem cells growth. Therefore, lnc34a role in CRC physiology must not be neglected and should be explored for devising therapeutic strategies for CRC. Despite their prolific role in development and differentiation of cells, there are certain limitations that have still impeded progress related to lncRNA as therapeutic strategy for various cancers [29]. However, advancements in the field of high-throughput technologies, and genome wide sequencing has begun to narrow the gaps related to lncRNA biology. It has now become plausible to circumscribe the expression pattern and tissue related expression of lncRNA. In addition to this development in the field of siRNA, anti-sense oligonucleotides (ASO) have made it easy to study the functionality of the lncRNA in different organs and tissues. IncRNA mediated silencing of target genes is an unmet challenge in CRC, therefore development of target specific ASO with limited side effects is worth exploring.

\section{Human 8q24 "Gene desert" the hotspot for CRC}

The human 8q24 gene desert is a hub for many lncRNAs which have been implicated to monitor Wnt signaling cascade [30]. Expression analysis studies have confirmed the presence of colon cancer associated Transcript 1 (CCAT-1), CCAT-1-L, CCAT-1-S, CCAT-2, CASC11 and several other $\ln c R N A s$ in this region [31]. The details of this region in regulating the growth and differentiation have been discussed here:

Colon cancer associated Transcript 1 (CCAT-1) also known as CARLo-5 is a gene located in close vicinity of the $M Y C$ oncogene [31]. There are two variants, namely $C C A T-1-S$ and $C C A T-1-L$, encoded by the CCAT-1 gene. $C C A T-1$ has been reported to be upregulated in almost

Table 1 LnCRNAs involved in Wnt signaling in CRC

\begin{tabular}{|c|c|c|}
\hline LncRNA & Targeted Wnt pathway & Effects \\
\hline CCAT1-S CARLO-5 & TCF4 expression through up-regulation of the SNPrs6983267 & Poor prognosis and low survival rate in CRCs \\
\hline CCAT-1-L & Interacts with the chromatin modeler CTCF and MYC expression & Growth and differentiation of CRC \\
\hline CCAT-2 & $\begin{array}{l}\text { Regulates the TCF7L2 expression through up-regulation of the } \\
\text { SNPs }\end{array}$ & $\begin{array}{l}\text { Poor prognosis and low survival rate in CRCs and promotes } \\
\text { metastasis and proliferation }\end{array}$ \\
\hline CASC11 & $\begin{array}{l}\text { Activates the expression of Beta-Catenin and modulates the } \\
\text { expression of MYC gene through SNP rs16902359 }\end{array}$ & $\begin{array}{l}\text { Elevates tumorigenesis and metastases of primary tumors to } \\
\text { lymph-nodes in CRC }\end{array}$ \\
\hline PVT1 & $\begin{array}{l}\text { Acts as scaffold RNA site that covers Threonine residue } 58 \text { and } \\
\text { controls a range of miRNAs such as the miR-1204, miR-1205, } \\
\text { miR-1206, miR-1207-5p, miR-1207-3p and miR-1208 }\end{array}$ & $\begin{array}{l}\text { Poor prognosis and low survival rate in CRCs and promotes } \\
\text { metastasis and proliferation }\end{array}$ \\
\hline Lnc34a & $\begin{array}{l}\text { Regulates the expression of miRNA-34a which acts on TCF7L2 } \\
\text { and beta-catenin and Notch signaling }\end{array}$ & Asymmetric growth of CRC stem cell \\
\hline RBM5-AS1 & $\begin{array}{l}\text { Beta-Catenin and SGK1, YAP1 and MYC via TCF7L2 transcription } \\
\text { factor }\end{array}$ & Growth and proliferation of CRC stem cells in vivo and in vitro \\
\hline ASCL2 & Beta-catenin production and interaction with TCF7L2 & Growth and stemness of CRC stem cells and intestinal cells \\
\hline WiNTRLINC1 & Beta-Catenin and ASCL2 expression & $\begin{array}{l}\text { Poor prognosis and low survival rate in CRCs and promotes } \\
\text { metastasis }\end{array}$ \\
\hline PCAT1 & $\begin{array}{l}\text { Regulates the expression of } L G R 5 \text { gene and Wnt signaling to } \\
\text { promote the expression of MYC }\end{array}$ & $\begin{array}{l}\text { Poor prognosis and low survival rate in CRCs and promotes } \\
\text { metastasis }\end{array}$ \\
\hline IncRNA H19 & $\begin{array}{l}\text { Regulates the expression of MYC and beta-catenin through } \\
\text { CDK8 production }\end{array}$ & Growth and proliferation of CRC \\
\hline$C C A L$ & $\begin{array}{l}\beta \text {-catenin/TCF7L2 and multidrug resistance gene } 1 \text { (MDR- } 1) \text { and } \\
\text { modulates the expression of AP } 2 a\end{array}$ & $\begin{array}{l}\text { Poor survival, devastating metastasis and resistance to adjuvant } \\
\text { chemotherapy in CRC }\end{array}$ \\
\hline
\end{tabular}




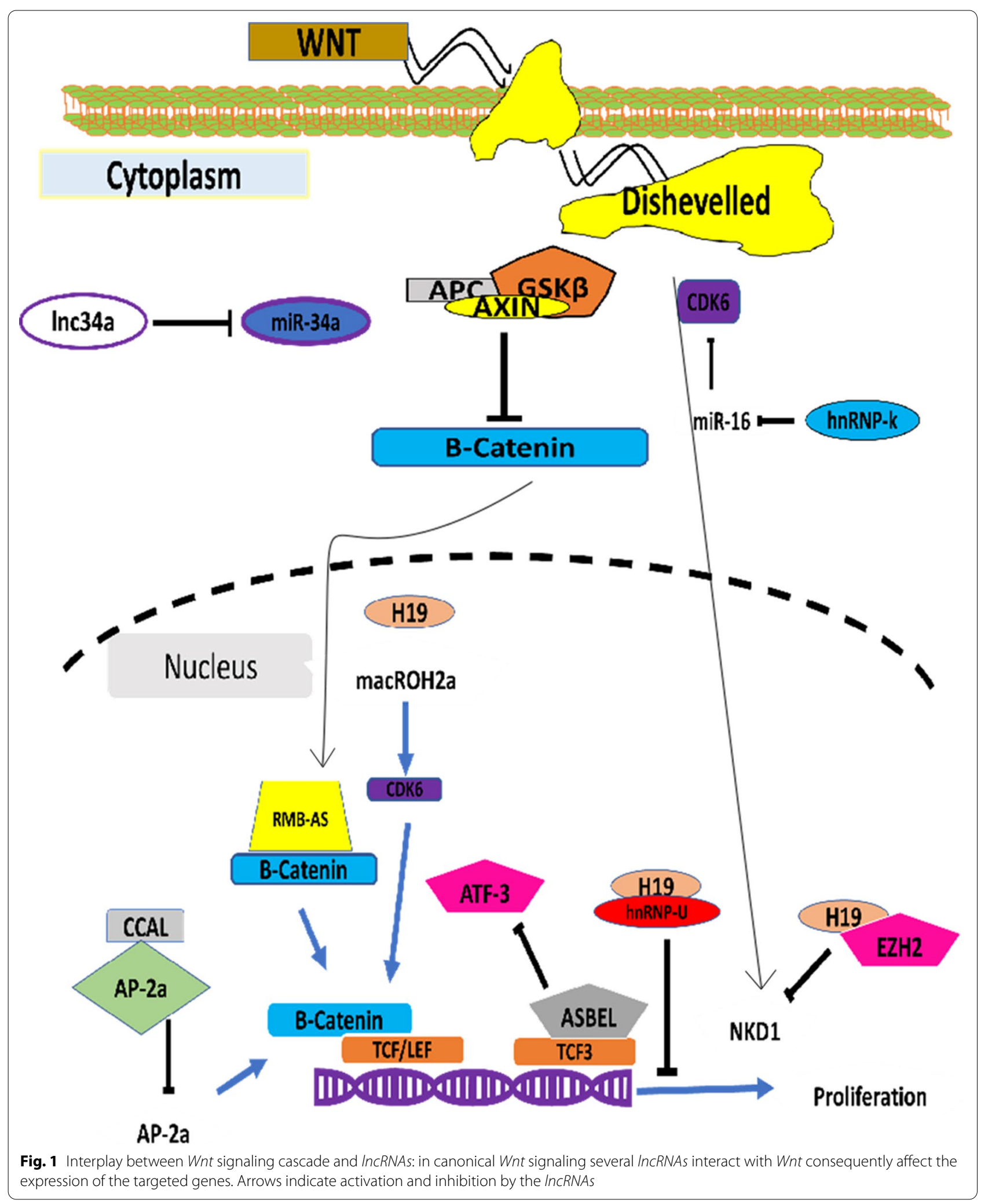


all stages of CRCs and its overexpression usually curtails poor prognosis and low survival rate in CRCs patients [31]. CCAT-1 overexpression and tumor progression has also been linked to other tumors such as breast cancer [32]. The isoform CCAT-1-S has been reported to regulate Wnt signaling effector TCF4 expression through upregulation of the SNPrs6983267 [28, 33]. rs6983267 is in the telomeric region of the CCAT-1-S isoform which is activated through the loop formed by the CCAT-1-S. Knock-down of CCAT-1-S significantly hampered CRC growth both in vivo and in vitro [32]. Furthermore, $C C A T-1-L$ has also been implemented to enhance cellular growth and proliferation of the CRC. CCAT-1-L overexpression has been found in several CRCs and xenograft mouse models [34]. CCAT-1-L interacts with the $M Y C$ gene at its promoter and facilitates effective transcription. CCAT-1-L interacts with the chromatin modeler $C T C F$, interaction between $C T C F$ and CCAT-1-L trigger chromosomal unwinding that in turn promotes the effective transcription of $M Y C$ and thus growth and differentiation of CRC [34]. From these findings, it can be deciphered that $C C A T-1$ acts as enhancer RNA that promotes the active transcription of $M Y C[34,35]$. This molecular interaction is complex as it involves the SNP, enhancer RNAs and modulation of $M Y C$ expression that ultimately leads to growth of CRC [35].

CCAT-2 is another IncRNA that has been investigated for its role in the progression and metastasis of CRC [36]. CCAT-2 has been implemented to play a decisive role in the progression of tumor by several ways. Genomic region encompassing CCAT-2 is highly conserved throughout the species, makings it indispensable for the transcription [37]. This region also contains the SNPrs6983267 a highly predisposing single nucleotide polymorphism affiliated with the CRC and prostate cancer [38]. Furthermore, $C C A T-2$ lies very close to the $M Y C$ gene, thus, $C C A T-2$ has a role in the Cis regulation of $M Y C$ gene [33]. CCAT-2 upregulation has been reported to enhance tumor progression and metastasis in microsatellite stable CRCs [39]. Additionally, these tumors also exhibited high levels of chromosomal instability. However, CCAT-2 was found downregulated in the microsatellite instable tumors with limited levels of Chromosomal instability [19]. These findings suggested that CCAT-2 expression was pivotal for enhancing the CRC progression in vitro [39]. Accumulating data have begun to suggest the involvement of $C C A T-2$ in trans regulation of the Wnt signaling cascade. The transcription factor like $7 \mathrm{~L} 2$ (TCF7L2) a transcription factor of Wnt signaling cascade is activated by the CCAT-2 lncRNA in the presence of DNA elements and enhancers and also under the influence of the SNPs [39]. The absence of DNA elements, scarcity of the enhancer and berated expression of SNPs greatly hampered the growth of intestinal cells of CRCs in vivo [39]. Recently, this non-coding RNA was reported to exert allele-specific effects on cancer metabolism by interaction with the splicing protein CFIm and ensuring alternative splicing of glutaminase [40]. In addition, multiple meta-analysis studies reported the prognostic value of CCAT-2 in predicting cancer patient survival [39].

Carlo- 7 also known as the CASC 11 is another lncRNA that has been investigated recently for its involvement in tumor progression. CASC11 is also a neighboring gene of the $M Y C$ [41]. This region also contains a single nucleotide polymorphism SNP rs16902359. CASC11 up-regulation is a hallmark in CRC tumor biology [41]. Overexpression of CASC1 curtails elevated tumorigenesis and metastases of primary tumors to lymph-nodes. Furthermore, CASC11 overexpression promotes the stability of heterogeneous ribonucleoprotein $\mathrm{K}(h n R N P-K)$ [41]. Stable $h n R N P-K$ prevents the proteasome mediated destruction of $\beta$-catenin in a feedback response manner and consequently, promote growth and differentiation of the tumor cell. CASC11 expression is modulated by the $M Y C$ protein. $M Y C$ protein binds to the promoter region of the CASC11 that facilitates CASC11 expression [41].

$P V T 1$ also known as pvt 1 oncogene is located downstream of the $M Y C$ gene and regulate translation of $M Y C$ gene [42]. PVT1 inhibits degradation of $M Y C$ gene by preventing phosphorylation at serine threonine residues. New studies have begun to shed light on the interaction between $M Y C$ protein and PVT1 RNA [42, 43]. PVT1 lncRNA acts as scaffold RNA site that covers Threonine residue 58 [42]. Thus, prevent phosphorylation and promote growth and differentiation of the CRC cells. PVT1 act as oncogene that facilitates the expression of $M Y C$ is confirmed by chromosome engineering. Both $M Y C$ and PVT1 are expressed in equal amounts in the HCT116 cell lines. The reduction of $P V T 1$ significantly reduced the cell growth in HCT116 cell lines [42]. while PVT1 overexpression has been linked to poor prognosis in patients with CRC [43]. Therefore, it can be used a diagnostic marker for the CRCs. The PVT1 gene cluster houses large number of miRNAs such as, miR-1204, miR-1205, miR1206, miR-1207-5p, miR-1207-3p and miR-1208 [44]. Their functionality is still bleak however; exploring the role of these miRNAs will enhance our understanding of PVT1 mediated tumor progression.

\section{LncRNAs and Wnt signaling in CRC stem cell development}

Wnt mediated differentiation of the cancer stem cells confer resistance to several drugs in CRC [45]. Furthermore, targeting this derailed Wnt signaling with $l n c R$ $N A s$ is a promising new strategy to be explored. Several lncRNAs have been reported that efficiently orchestrate the CRC stem cells development and differentiation. 
Advancements in the field of genome wide analysis and high throughput technology have begun to reveal the depth of tumor biology.

Lnc34a has been implicated to suppress the expression of the miR-34a as it is transcribed in anti-sense orientation. Like other cancers, CRC has been reported to contain loss of function mutation of miR-34a [46]. miR-34a has been involved in regulation of Wnt signaling cascades at both transcriptional and translational levels [47]. miR$34 a$ directly targets the $\beta$-catenin and promotes its proteasome mediated degradation [47]. miR-34a also reduces the expression of Wnt targeted gene by interacting with the transcription factor TCF7L2 [48]. These interactions hamper the Wnt mediated differentiation of the tumor cells [49]. It has come to light less lately that $m i R-34 a$ also interacts with the Notch signaling pathway and directly triggers the asymmetric growth of CRC stem cell via a feedforward loop with Numb proteins [50]. New finding has revealed the involvement of a $\operatorname{lncRNA}(\ln c 34 a)$ in modulation of the expression of the miR-34a. Furthermore, $\ln c 34 a$ interactions with epigenetic regulators DNA methyltransferase 3a (Dnmt3a), histone deacetylase 1 (HDAC1) and PHB2 successfully hinder the expression of the $m i R-34 a$ in the absence of $P 53$ protein. Altogether, these findings indicate the important role of $\operatorname{lnc} 34 a$ in modulation of miR-34a expression and in growth and differentiation of the CRC stem cells [51]. However, $\operatorname{lnc} 34 a$ has a dual role in development of CRC stem cells. In mice model, it has been delineated that $\ln c 34 a$ promotes the growth of CRC stem cells via inhibition of $m i R-34 a$ expression but the growth was limited to only first daughter cells [51]. Moreover, $\ln c 34 a$ was found to be unequally divided in the CRC stem cells and this unequal distribution promoted the suppression of $m i R-34 a$ in one daughter cells while increase in the growth of the other CRC stem cells [51]. Lnc34a has also been found to upregulate the in the later stages of CRC growth indicating the fact that miRNA-lnRNA interplay is crucial for the development and differentiation of CRC [51]. The functional importance of the lncRNA-miRNA interaction can glean the structural framework that potentiates growth promoting pathways such as the Notch and Wnt.

LncRNA known as the RBM5-AS1 is reported to be up-regulated during the early stages of the CRC [52]. ASOs and siRNA-based approaches applied to silence this lncRNA resulted in down-regulation of the $\mathrm{Wnt}$ Signaling cascade and in turn minimal growth of CRC [52]. However, forced expression of RBM5-AS1 promptly increased the cell division in early stage CRC Stem cells. Functional analysis studies confirmed that RBM5-AS1 directly interacts with the $\beta$-catenin and thus, facilitate the expression of oncogenes (SGK1, YAP1 and $M Y C$ ) under the influence of transcription factor TCF7L2 complex [52].
Wnt signaling plays a crucial role in maintaining the stemness of intestinal cells by interacting with transcription factors such as the ASCL2 [53]. $\beta$-catenin is released from receptor ligand interaction progressively migrates to the nucleus where it interacts with the transcription factor TCF7L2 in the presence of ASCL2 [54]. This in turn promotes consistent cell growth of intestinal cells. Chip-sequencing data has demonstrated the role of a lncRNA in promotion of the cancer stemness in the intestinal cells by modulating the expression of ASCL2 [54]. Newly defined lncRNA WiNTRLINC1 (Wht-regulated lincRNA-1) has been reported to interfere with the expression of the ASCL2. Chip-seq data confirmed that WiNTRLINC1 facilitates the recruitment of $\beta$-catenin/ TCF7L2 regulatory elements close to the ASCL2 via formation of loop that comprehensively aids in maintenance of stemness in the intestinal cells. Expression analysis studies have confirmed overexpression of $\mathrm{WiN}$ TRLINClin CRC tumors [54]. The interaction between $\beta$-catenin and WiNTRLINC1 resulted in increased invasiveness, metastases and poor prognosis in the CRC.

IncTCF is another lncRNA that plays a pivotal role in the development and differentiation of the cancer stem cells [24]. However, its role as oncogenic lncRNA in CRC has less come to light, lncTCF endorse the expression of the Wnt signaling cascade that in turn promoted the growth of the CRC cells [24]. Increased expression of the IncTCF has been affiliated with the poor prognosis and increased differentiation of the CRC [24].

Another IncRNA PCAT1 has also been enlisted to enhance proliferation of the CRC via up-regulation of the MYC [45]. PCAT1 overexpression leads to poor prognosis and low survival rates in patients with CRC [46]. Wnt signaling cascade is indispensable for tailoring the new outlook for both the normal as well as cancer stem cells $[55,56]$. IncRNAs curtails the oncogenic effects of Wnt signaling by regulating the expression key proteins at both transcription and translation levels [57]. It has been well established that aberrant Wnt signaling mediated regulation of LGR5 gene trigger stem cell differentiation and asymmetric cell division.

\section{LncRNAs as activator of proliferation, metastasis and invasion in CRC}

IncRNA $\boldsymbol{H} 19$ has been reported to inflict death punches in CRC. $H 19$ was discovered in early $90 \mathrm{~s}$ and its presence is instrumental in embryonic development [58]. H19 involvement in various cancers has been well documented [59]. H19 interplays with the variety of miRNAs either inhibiting their expression (let7 and miR-106a) or facilitating their transcription (miR-675) [60]. A recent study has demonstrated that enhanced expression of $\mathbf{H 1 9}$ IncRNA was related to poor prognosis of various human 
cancers. Suppression of $H 19$ resulted in increased cell survival and reduced migration in CRC [61]. H19 interaction with the miRNA let-7 and $M Y C$ is well known for tumor progression, however, recently microarraybased study has surfaced the interplay between $H 19$ and $\beta$-catenin, that triggers growth in Hepatocellular carcinoma via up-regulation of the $C D K 8$ expression $[62,63]$. Further, $H 19$ acts as catalyst that superficially regulates the expression of Wnt targeted genes as well as the $M Y C$ gene in many cancers [61-63]. Altogether, these findings suggest $H 19$ as an exclusive interpreter in stimulating as well as inhibiting the cellular growth. H19 interaction triggers the $C D K 8$ production through Histone modifications. It interacts with the hnRNP and prevents the downstream signaling of Wnt pathway that leads to differentiation suppression of the liver cells [64]. From these perspectives it is clearly demonstrated that H19 lncRNA although very small in size, can prove out to be possible diagnostic marker for CRCs. HI9 has been reported to effect miRNA let-7 activity, induce regulation of CDK8 through interplay with $\beta$-catenin and monitor the methylation at genome wide levels [65]. These findings suggested that the lncRNA H19 as therapeutic candidate for targeting Wnt mediated signaling cascade in CRC.

IncRNA CCAL intensify the overall CRC progression. Poor survival, devastating metastasis and resistance to adjuvant chemotherapy are the salient features associated with $C C A L$ [66]. CCAL confer chemotherapy resistance by indirectly modulating the expression of Wnt targeted genes such as $\beta$-catenin/TCF7L2 and multidrug resistance gene $1(M D R-1)$. CCAL interacts with $A P 2 \alpha$ protein and promotes the degradation of $A P 2 \alpha$, a negative regulator of $\beta$-catenin/TCF7L2 interaction, in CRC, and thus indirectly activates $W n t$ signaling [66]. This in turn promotes the expression of MDR1. MDR1 encodes the protein P-glycoprotein 1 whose overexpression facilitates drug resistance in majority of CRC [66].

CTD903 is another lncRNA whose ectopic expression has been related to mitigate growth of the CRC [67]. However, its downregulation resulted in the upregulation of the $\beta$-catenin which consequently, promoted growth and differentiation of CRC in vivo [67]. Furthermore, CTD903 has been investigated for its role in the promotion of the epithelial-mesenchymal transition (EMT). CTD903 reduced expression promoted EMT in CRC with an increased expression of transcription factors TWIST, SNAIL and vimentin. Additionally, there was reduction in the expression of epithelial marker ZO-1 [67]. However, the exact mechanism that elaborate the CTD903 downregulation promote Wnt mediated EMT remains to be explored.

BTG3-AS1 also referred to as ASBEL is another lncRNA that has been implemented to play crucial role in CRC proliferation and metastasis [68]. A recent study using Chip-Seq and RNA-seq confirmed that the knock down of the $A S B E L$ greatly reduced tumor growth in mice model. ASBEL interacts with the Transcription factor 3. TCF3 is direct target of $\beta$-catenin. $\beta$-catenin interaction with the TCF3 promotes the transcription of the $A T F 3$ that accentuate tumor proliferation [68]. It can be concluded that $A S B E L$ interaction with Wnt signaling cascade promote tumor progression in CRC.

IncRNA GAS5 (growth arrest specific 5) has been investigated to play a crucial role in prevention of angiogenesis, invasion and metastasis of the CRC [69]. A recent study shed light on the anti-proliferative aspects of GAS5 in CRC. Wnt signaling abrasion is a hall mark of CRC and GAS5 overexpression hampers the angiogenesis of the CRC [69]. Small interfering RNA approach confirmed that the inhibition of the GAS5 resulted in elevated growth and angiogenesis in CRC cell lines [69]. However, the exact mechanism by which GAS5 inhibits Wnt signaling cascade is still austere.

A recently characterized lncRNA, IncRNA-APC1 has been evidenced to play a decisive role in the pathogenesis of the CRC [70]. Microarray based study confirmed that down regulation of $\operatorname{lncRNA-APC1}$ was significant to exacerbate metastasis and invasiveness of CRC [70]. However, forced expression of $\ln C R N A-A P C 1$ significantly hampered cellular growth and differentiation of the CRC. Furthermore, APC1 expression was sufficient to inhibit CRC cell growth, metastasis, and tumor angiogenesis by suppressing exosome production through the direct binding of Rab5b mRNA and a reduction of its stability. Importantly, exosomes derived from $\ln R R N A$ $A P C 1$-silenced CRC cells promoted angiogenesis by activating the MAPK pathway in endothelial cells [70]. These findings shed lights on the implementation of the lncRNAs for a diagnosis as well as therapeutics in CRC.

LncRNA SLCO4A1-AS1 has been reported to relate to tumor proliferation and metastasis [71]. Knock-down of SLCO4A1-AS1 resulted in overall greater proliferation and metastasis in vitro. SLCO4A1-AS1 directly interacts with the $\beta$-catenin and facilitates the expression of oncogenes. The Glycogen synthetase kinase $\beta$ (GSK $\beta$ ) inhibits the expression of $\beta$-catenin and also inhibitsproliferation [71]. However, SLCO4A1-AS1 interacts with $\beta$-catenin, stabilizes $\beta$-catenin and prevents its phosphorylation by the GSK $\beta$ that in turn promote differentiation, invasion and metastasis of CRC cells [71].

NEAT1 has also been reported to play a role in CRC progression. A recent study has delineated the mechanism responsible for the CRC under the influence of NEAT1 [72]. NEAT1 indirectly promotes the activation of Wnt signaling cascade through activation of the Death domain Protein (DDX5). Upregulated NEAT1 
interaction with the DDX5 protein triggers the Wnt signaling in CRC. This indirect activation promotes metastasis and invasiveness of CRC [72]. This study signifies the importance of NEAT1/DDX5/Wnt cascade as therapeutic target for the treatment of the CRC.

IncRNA zinc finger E-box binding homeobox 2 anti-sense 1 (ZEB1-AS1) has been reported to act as oncogenic lncRNA that promote cell proliferation [73]. $Z E B-A S 1$ knockdown resulted in lower rates of proliferation and increased apoptosis. Furthermore, bioinformatic data suggest that $m i R-181 a-5 p$ has a role in orchestrating the function of $Z E B-A S 1$. miR-181a-5p negatively modulated the expression of the $Z E B-A S 1$ as confirmed by the luciferase and RIP assay. This study suggested that $Z E B-$ $A S 1$, act as a molecular sponge for miR-181a-5p [73]. These findings revealed that ZEB-AS1 is an oncogenic lncRNA that promotes proliferation of CRC cells.

qRT-PCR and knock down expression analysis revealed the involvement of HOX transcript antisense RNA (HOTAIR) in proliferation and chemoresistance of CRC [22]. HOTAIR is generally up-regulated in the CRC tumors as compared to normal tissue and its overexpression deterred apoptosis. However, miR-203a-3p overexpression elevated apoptosis and inhibited proliferation in vitro [74]. HOTAIR promoted the expression of the $\beta$-catenin and TLE family related transcript protein GRG5 via inhibition of miR-203a-3p. HOTAIR mediated overexpression of the $\beta$-catenin triggered cell growth and chemoresistance. The overexpression of miR-203a-3p significantly reduced the proliferation and chemoresistance [74]. These findings suggested the oncogenic role of HOTAIR in the development of the CRC.

Small nuclear host gene 1 (SNHG1) is another lncRNA whose upregulation enables CRC progression and metastasis [75]. Recent in vitro experiments have indicated that up-regulation of the $S N H G 1$ promotes the expression of the $\beta$-catenin and transcription factor-4 (TCF-4). In addition to this $S N G H 1$ has also been implemented to elevate the expression of the Cyclin D1 and membrane metalloprotease-9 [25]. These findings indicated that SNGH1 is upregulated in CRC and act as an oncogenic lncRNA which can be used as a diagnostic marker as well as a therapeutic target for CRC.

IncRNA linc00675 has been reported for inhibiting proliferation and metastases in different cancers. However, a recently surfaced study has delineated linc00675 role in CRC. This finding suggested that linc00675 has an anti-proliferative role in CRC. linc00675 interplays with the $m i R-942$ and prevents proliferation and metastases. linc00675 was found to be expressed in all CRC tissues and prevented the expression of $m i R-942$, however, $m i R-942$ mimics significantly increased the expression of $W n t / \beta-$ catenin pathways and increased differentiation in vivo [76].
These studies shown the importance of linc00675 as an potential diagnostic and therapeutic target for CRC.

\section{Conclusion}

Wht signaling controls a plethora of cellular processes in CRC. Cancer cell growth, differentiation, metastasis, drug resistance and disease relapse are tightly influenced by the abraded Wnt signaling. Therefore, Wnt signaling cascade is indispensable for the tumor cell maintenance. lncRNAs are tiny molecules that interact with the $\mathrm{Wnt}$ signaling in various ways. Interaction between lncRNA, Wnt signaling and corresponding molecules results in the orchestration of various cellular processes responsible for cell fate determination, development, differentiation and metastasis. The exact mechanism responsible for governing these interactions between lncRNA and Wnt is still bleak and requires more industrious efforts to delineate these mechanisms. This has become a stumbling block in the voyage for discovering new therapeutics for CRC. Recent advances in microarray, single molecule visualization techniques, RNA-sequencing, and methylation profiling will enable us to identify the hidden mysteries of lncRNA biology and interaction with Wnt signaling in CRC. Furthermore, clinical significance of $\operatorname{lncRNAs}$ in CRC can be illustrated by the use of large-scale database analysis. More efforts are required to understand the primary, secondary and tertiary structures of the lncRNAs as it will enable us to forecast structural and functional interactions at molecular levels. Furthermore, exploring the interplay between lncRNA and Wnt will bring us a step closer towards new therapeutic breakthroughs in CRC. Also, the advances on mechanism of understanding $\operatorname{lncRNAs}$ in Wnt signaling might bring novel candidates as biomarkers and therapeutics for CRC. Furthermore, single-cell sequencing may enable us to design oligonucleotide-based drugs and will help to achieve the potential of lncRNA as an alternative cancer therapy.

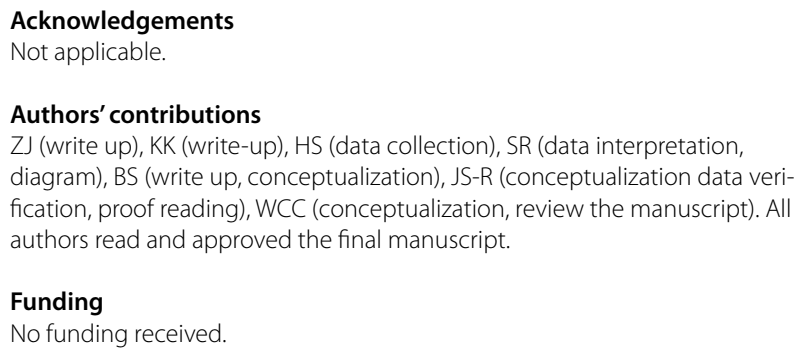

Availability of data and materials

Yes.

Ethics approval and consent to participate Not applicable.

Consent for publication

Not applicable. 


\section{Competing interests}

No competing interest.

\section{Author details}

${ }^{1}$ Office for Research Innovation and Commercialization, Lahore Garrison University, Sector-C, Phase VI, DHA, Lahore, Pakistan. ${ }^{2}$ Atta-ur-Rahman School of Applied Biosciences (ASAB), National University of Sciences and Technology (NUST), Islamabad 44000, Pakistan. ${ }^{3}$ Department of Biotechnology, Balochistan University of Information Technology, Engineering and Management Sciences, Quetta, Pakistan. ${ }^{4}$ Department of Biotechnology, University of Central Punjab, Lahore, Pakistan. ${ }^{5}$ Noncommunicable Diseases Research Center, Bam University of Medical Sciences, Bam, Iran. ${ }^{6}$ Student Research Committee, School of Medicine, Bam University of Medical Sciences, Bam, Iran. 7 Phytochemistry Research Center, Shahid Beheshti University of Medical Sciences, Tehran, Iran. ${ }^{8}$ Department of Clinical Oncology, Queen Elizabeth Hospital, 30 Gascoigne Road, Hong Kong, China.

Received: 7 April 2020 Accepted: 9 July 2020

Published online: 20 July 2020

\section{References}

1. SEER S: Stat Database: Incidence_-SEER 9 Regs Research Data, November 2013 Sub (1992-2011). Surveillance, Epidemiology, and End Results (SEER) Program 2016.

2. DESA U: United Nations Department of Economic and Social Affairs, Population Division. World Population Prospects: The 2015 revision, key findings and advance tables. Working Paper No. ESA/P/WP. 241; 2015.

3. Farooqi AA, de la Roche M, Djamgoz MBA, Siddik ZH. Overview of the oncogenic signaling pathways in colorectal cancer: mechanistic insights. Seminars in cancer biology. Cambridge: Academic Press; 2019.

4. Fearon ER, Vogelstein B. A genetic model for colorectal tumorigenesis. Cell. 1990;61(5):759-67.

5. Fearon ER. Molecular genetics of colorectal cancer. Annu Rev Pathol. 2011;6:479-507.

6. van Amerongen R, Nusse R. Towards an integrated view of Wnt signaling in development. Development. 2009;136(19):3205-14.

7. Clevers $H$. Wnt/ $\beta$-catenin signaling in development and disease. Cell. 2006;127(3):469-80.

8. Kim NH, Kim HS, Kim N-G, Lee I, Choi H-S, Li X-Y, Kang SE, Cha SY, Ryu JK, Na JM. p53 and microRNA-34 are suppressors of canonical Wnt signaling. Sci Signal. 2011;4(197):ra71-ra71.

9. Huarte M. The emerging role of IncRNAs in cancer. Nat Med. 2015;21(11):1253.

10. Nusse $\mathrm{R}$, Clevers H. Wnt/ß-catenin signaling, disease, and emerging therapeutic modalities. Cell. 2017;169(6):985-99.

11. Reya T, Clevers H. Wnt signalling in stem cells and cancer. Nature. 2005;434(7035):843.

12. Hart MJ. de los Santos R, Albert IN, Rubinfeld B, Polakis P: downregulation of $\beta$-catenin by human Axin and its association with the APC tumor suppressor, $\beta$-catenin and GSK3 $\beta$. Curr Biol. 1998;8(10):573-81.

13. Stamos JL, Weis WI. The $\beta$-catenin destruction complex. Cold Spring Harbor Perspect Biol. 2013;5(1):a007898.

14. Ikeda S, Kishida S, Yamamoto H, Murai H, Koyama S, Kikuchi A. Axin, a negative regulator of the Wnt signaling pathway, forms a complex with GSK-3 $\beta$ and $\beta$-catenin and promotes GSK-3 $\beta$-dependent phosphorylation of $\beta$-catenin. EMBO J. 1998;17(5):1371-84.

15. Morin PJ, Sparks AB, Korinek V, Barker N, Clevers H, Vogelstein B, Kinzler $\mathrm{KW}$. Activation of beta-catenin-Tcf signaling in colon cancer by mutations in beta-catenin or APC. Science (New York, NY). 1997;275(5307):1787-90.

16. Korinek V, Barker N, Morin PJ, van Wichen D, de Weger R, Kinzler KW, Vogelstein $\mathrm{B}$, Clevers $\mathrm{H}$. Constitutive transcriptional activation by a betacatenin-Tcf complex in APC-/- colon carcinoma. Science (New York, NY). 1997;275(5307):1784-7.

17. Djebali S, Davis CA, Merkel A, Dobin A, Lassmann T, Mortazavi A, Tanzer A, Lagarde J, Lin W, Schlesinger F. Landscape of transcription in human cells. Nature. 2012;489(7414):101.

18. Calin GA, Dumitru CD, Shimizu M, Bichi R, Zupo S, Noch E, Aldler H, Rattan S, Keating M, Rai K. Frequent deletions and down-regulation of
micro-RNA genes miR15 and miR16 at 13q14 in chronic lymphocytic leukemia. Proc Natl Acad Sci. 2002;99(24):15524-9.

19. Ling H, Vincent K, Pichler M, Fodde R, Berindan-Neagoe I, Slack FJ, Calin GA. Junk DNA and the long non-coding RNA twist in cancer genetics. Oncogene. 2015;34(39):5003-11.

20. Wang KC, Chang HY. Molecular mechanisms of long noncoding RNAs. Mol Cell. 2011;43(6):904-14.

21. Beroukhim R, Mermel CH, Porter D, Wei G, Raychaudhuri S, Donovan J, Barretina J, Boehm JS, Dobson J, Urashima M, et al. The landscape of somatic copy-number alteration across human cancers. Nature. 2010;463(7283):899-905.

22. Xiao Z, Qu Z, Chen Z, Fang Z, Zhou K, Huang Z, Guo X, Zhang Y. LncRNA HOTAIR is a prognostic biomarker for the proliferation and chemoresistance of colorectal cancer via MiR-203a-3p-mediated Wnt/ss-catenin signaling pathway. Cell Physiol Biochem. 2018;46(3):1275-85.

23. Jung Y-S, Park J-I. Wnt signaling in cancer: therapeutic targeting of Wnt signaling beyond $\beta$-catenin and the destruction complex. Exp Mol Med. 2020;10:1-9.

24. Li T, Zhu J, Wang X, Chen G, Sun L, Zuo S, Zhang J, Chen S, Ma J, Yao Z, et al. Long non-coding RNA IncTCF7 activates the Wnt/beta-catenin pathway to promote metastasis and invasion in colorectal cancer. Oncol Lett. 2017;14(6):7384-90.

25. Zhu Y, Li B, Liu Z, Jiang L, Wang G, Lv M, Li D. Up-regulation of IncRNA SNHG1 indicates poor prognosis and promotes cell proliferation and metastasis of colorectal cancer by activation of the Wnt/beta-catenin signaling pathway. Oncotarget. 2017;8(67):111715-27.

26. Shan Z, An N, Qin J, Yang J, Sun H, Yang W. Long non-coding RNA Linc00675 suppresses cell proliferation and metastasis in colorectal cancer via acting on miR-942 and Wnt/beta-catenin signaling. Biomed Pharmacother Biomed Pharmacother. 2018;101:769-76.

27. Turdo A, Veschi V, Gaggianesi M, Chinnici A, Bianca P, Todaro M, Stassi G. Meeting the challenge of targeting cancer stem cells. Front Cell Dev Biol. 2019;7:16.

28. Haiman CA, Le Marchand L, Yamamato J, Stram DO, Sheng X, Kolonel LN, Wu AH, Reich D, Henderson BE. A common genetic risk factor for colorectal and prostate cancer. Nat Genet. 2007;39(8):954-6.

29. Ediriweera MK, Tennekoon KH, Samarakoon SR. In vitro assays and techniques utilized in anticancer drug discovery. J Appl Toxicol. 2019;39(1):38-71

30. Wright JB, Brown SJ, Cole MD. Upregulation of C-MYC in cis through a large chromatin loop linked to a cancer risk-associated singlenucleotide polymorphism in colorectal cancer cells. Mol Cell Biol. 2010;30(6):1411-20

31. Archbold $H$, Yang Y, Chen L, Cadigan K. How do they do Wnt they do?: regulation of transcription by the Wnt/ $\beta$-catenin pathway. Acta Physiol. 2012:204(1):74-109.

32. Pomerantz MM, Ahmadiyeh $N$, Jia L, Herman P, Verzi MP, Doddapaneni $H$, Beckwith CA, Chan JA, Hills A, Davis M, et al. The 8q24 cancer risk variant rs6983267 shows long-range interaction with MYC in colorectal cancer. Nat Genet. 2009;41(8):882-4.

33. Tuupanen S, Turunen M, Lehtonen R, Hallikas O, Vanharanta S, Kivioja T, Bjorklund M, Wei G, Yan J, Niittymaki I, et al. The common colorectal cancer predisposition SNP rs6983267 at chromosome 8q24 confers potential to enhanced Wnt signaling. Nat Genet. 2009;41(8):885-90.

34. Kim T, Cui R, Jeon YJ, Lee JH, Lee JH, Sim H, Park JK, Fadda P, Tili E, Nakanishi $\mathrm{H}$, et al. Long-range interaction and correlation between MYC enhancer and oncogenic long noncoding RNA CARLo-5. Proc Natl Acad Sci USA. 2014;111(11):4173-8.

35. Guo X, Hua Y. CCAT1: an oncogenic long noncoding RNA in human cancers. J Cancer Res Clin Oncol. 2017;143(4):555-62.

36. Shi D, Wu F, Gao F, Qing X, Shao Z. Prognostic value of long non-coding RNA CCAT1 expression in patients with cancer: a meta-analysis. PloS ONE. 2017;12(6):e0179346

37. Xiang JF, Yin QF, Chen T, Zhang Y, Zhang XO, Wu Z, Zhang S, Wang HB, Ge J, Lu X, et al. Human colorectal cancer-specific CCAT1-L IncRNA regulates long-range chromatin interactions at the MYC locus. Cell Res. 2014;24(5):513-31.

38. Lu L, Qi H, Luo F, Xu H, Ling M, Qin Y, Yang P, Liu X, Yang Q, Xue J, et al. Feedback circuitry via let-7c between IncRNA CCAT1 and c-Myc is involved in cigarette smoke extract-induced malignant transformation of HBE cells. Oncotarget. 2017;8(12):19285-97. 
39. Ling H, Spizzo R, Atlasi Y, Nicoloso M, Shimizu M, Redis RS, Nishida N, Gafa $\mathrm{R}$, Song J, Guo Z, et al. CCAT2, a novel noncoding RNA mapping to 8q24, underlies metastatic progression and chromosomal instability in colon cancer. Genome Res. 2013;23(9):1446-61.

40. Shen P, Pichler M, Chen M, Calin G, Ling H. To Wnt or lose: the missing non-coding linc in colorectal cancer. Int J Mol Sci. 2017;1 18(9):2003.

41. Zhang Z, Zhou C, Chang Y, Zhang Z, Hu Y, Zhang F, Lu Y, Zheng L, Zhang W, Li X, et al. Long non-coding RNA CASC11 interacts with hnRNP-K and activates the WNT/beta-catenin pathway to promote growth and metastasis in colorectal cancer. Cancer Lett. 2016;376(1):62-73.

42. Tseng YY, Moriarity BS, Gong W, Akiyama R, Tiwari A, Kawakami H, Ronning P, Reuland B, Guenther K, Beadnell TC, et al. PVT1 dependence in cancer with MYC copy-number increase. Nature. 2014;512(7512):82-6.

43. Takahashi Y, Sawada G, Kurashige J, Uchi R, Matsumura T, Ueo H, Takano Y, Eguchi H, Sudo T, Sugimachi K, et al. Amplification of PVT-1 is involved in poor prognosis via apoptosis inhibition in colorectal cancers. Br J Cancer. 2014;110(1):164-71.

44. Huppi K, Volfovsky N, Runfola T, Jones TL, Mackiewicz M, Martin SE, Mushinski JF, Stephens R, Caplen NJ. The identification of microRNAs in a genomically unstable region of human chromosome 8q24. Mol Cancer Res MCR. 2008;6(2):212-21.

45. Clevers $\mathrm{H}$, Nusse R. Wnt/ $\beta$-catenin signaling and disease. Cell. 2012;149(6):1192-205.

46. Hermeking $H$. The miR-34 family in cancer and apoptosis. Cell Death Differ. 2010;17(2):193.

47. Hashimi ST, Fulcher JA, Chang MH, Gov L, Wang S, Lee B. MicroRNA profiling identifies miR-34a and miR-21 and their target genes JAG1 and WNT1 in the coordinate regulation of dendritic cell differentiation. Blood. 2009;114(2):404-14.

48. Huang K, Zhang J-X, Han L, You Y-P, Jiang T, Pu P-Y, Kang C-S. MicroRNA roles in beta-catenin pathway. Mol Cancer. 2010;9(1):252.

49. Sun F, Fu H, Liu Q, Tie Y, Zhu J, Xing R, Sun Z, Zheng X. Downregulation of CCND1 and CDK6 by miR-34a induces cell cycle arrest. FEBS Lett. 2008;582(10):1564-8.

50. Bu P, Wang L, Chen KY, Srinivasan T, Murthy PK, Tung KL, Varanko AK, Chen $\mathrm{HJ}$, Ai Y, King S, et al. A miR-34a-numb feedforward loop triggered by inflammation regulates asymmetric stem cell division in intestine and colon cancer. Cell Stem Cell. 2016;18(2):189-202.

51. Wang L, Bu P, Ai Y, Srinivasan T, Chen HJ, Xiang K, Lipkin SM, Shen X. A long non-coding RNA targets microRNA miR-34a to regulate colon cancer stem cell asymmetric division. Elife. 2016;5:e14620.

52. Di Cecilia S, Zhang F, Sancho A, Li S, Aguilo F, Sun Y, Rengasamy M, Zhang W, Del Vecchio L, Salvatore F, et al. RBM5-AS1 is critical for self-renewal of colon cancer stem-like cells. Cancer Res. 2016;76(19):5615-27.

53. van der Flier LG, van Gijn ME, Hatzis P, Kujala P, Haegebarth A, Stange $D E$, Begthel $H$, van den Born M, Guryev V, Oving I, et al. Transcription factor achaete scute-like 2 controls intestinal stem cell fate. Cell. 2009;136(5):903-12.

54. Giakountis A, Moulos P, Zarkou V, Oikonomou C, Harokopos V, Hatzigeorgiou AG, Reczko M, Hatzis P. A positive regulatory loop between a Wnt-regulated non-coding RNA and ASCL2 controls intestinal stem cell fate. Cell Rep. 2016;15(12):2588-96.

55. Tang Q, Chen J, Di Z, Yuan W, Zhou Z, Liu Z, Han S, Liu Y, Di M, Shu X. TM4SF1 promotes EMT and cancer stemness via Wnt/ $\beta$-catenin/SOX2 pathway in colorectal cancer. J Exp Clin Cancer Res. 2020. https://doi.org/ 10.21203/rs.3.rs-23983/v.

56. LV J, Chen F-K, Liu C, Liu P-J, Feng Z-P, Jia L, Yang Z-X, Hou F, Deng Z-Y. Zoledronic acid inhibits thyroid cancer stemness and metastasis by repressing M2-like tumor-associated macrophages induced Wnt/ßcatenin pathway. Life Sci. 2020. https://doi.org/10.1016/j.lfs.2020.117925.

57. Sun W, Chen G, Wang J, Yu X, Hao X, Hu M. Long non-coding RNA OR3A4 facilitates cell proliferation and migration in colorectal cancer through the Wnt/ß-catenin signaling pathway. Eur Rev Med Pharm Sci. 2020;24(10):5360-6.

58. Brannan $\mathrm{Cl}$, Dees $\mathrm{EC}$, Ingram RS, Tilghman SM. The product of the $\mathrm{H} 19$ gene may function as an RNA. Mol Cell Biol. 1990;10(1):28-36.

59. Zhang Y, Shields T, Crenshaw T, Hao Y, Moulton T, Tycko B. Imprinting of human H19: allele-specific CpG methylation, loss of the active allele in Wilms tumor, and potential for somatic allele switching. Am J Hum Genet. 1993;53(1):113-24.

60. Raveh E, Matouk IJ, Gilon M, Hochberg A. The H19 Long non-coding RNA in cancer initiation, progression and metastasis-a proposed unifying theory. Mol Cancer. 2015;14:184

61. Liang W-C, Fu W-M, Wong C-W, Wang Y, Wang W-M, Hu G-X, Zhang L, Xiao L-J. Wan DC-C, Zhang J-F: the IncRNA H19 promotes epithelial to mesenchymal transition by functioning as miRNA sponges in colorectal cancer. Oncotarget. 2015;6(26):22513.

62. Kallen AN, Zhou XB, Xu J, Qiao C, Ma J, Yan L, Lu L, Liu C, Yi JS, Zhang H, et al. The imprinted H19 IncRNA antagonizes let-7 microRNAs. Mol Cell. 2013;52(1):101-12.

63. Ma C, Nong K, Zhu H, Wang W, Huang X, Yuan Z, Ai K. H19 promotes pancreatic cancer metastasis by derepressing let-7's suppression on its target HMGA2-mediated EMT. Tumor Biol. 2014;35(9):9163-9.

64. Martens-Uzunova ES, Böttcher R, Croce CM, Jenster G, Visakorpi T, Calin GA. Long noncoding RNA in prostate, bladder, and kidney cancer. Eur Urol. 2014;65(6):1140-51.

65. Ohtsuka M, Ling H, Ivan C, Pichler M, Matsushita D, Goblirsch M, Stiegelbauer V, Shigeyasu K, Zhang X, Chen M, et al. H19 noncoding RNA, an independent prognostic factor, regulates essential Rb-E2F and CDK8-beta-catenin signaling in colorectal cancer. EBioMedicine. 2016;13:113-24.

66. Ma Y, Yang Y, Wang F, Moyer MP, Wei Q, Zhang P, Yang Z, Liu W, Zhang $H$, Chen N, et al. Long non-coding RNA CCAL regulates colorectal cancer progression by activating Wnt/beta-catenin signalling pathway via suppression of activator protein 2alpha. Gut. 2016;65(9):1494-504.

67. Yuan Z, Yu X, Ni B, Chen D, Yang Z, Huang J, Wang J, Chen D, Wang L. Overexpression of long non-coding RNA-CTD903 inhibits colorectal cancer invasion and migration by repressing Wnt/beta-catenin signaling and predicts favorable prognosis. Int J Oncol. 2016;48(6):2675-85.

68. Taniue K, Kurimoto A, Takeda Y, Nagashima T, Okada-Hatakeyama M, Katou Y, Shirahige K, Akiyama T. ASBEL-TCF3 complex is required for the tumorigenicity of colorectal cancer cells. Proc Natl Acad Sci. 2016;113(45):12739-44.

69. Song J, Shu H, Zhang L, Xiong J. Long noncoding RNA GAS5 inhibits angiogenesis and metastasis of colorectal cancer through the Wnt/ß-catenin signaling pathway. J Cell Biochem. 2019;120(5):6937-51.

70. Wang FW, Cao CH, Han K, Zhao YX, Cai MY, Xiang ZC, Zhang JX, Chen JW, Zhong LP, Huang Y, et al. APC-activated long noncoding RNA inhibits colorectal carcinoma pathogenesis through reduction of exosome production. J Clin Investig. 2019;129(2):727-43.

71. Yu J, Han Z, Sun Z, Wang Y, Zheng M, Song C. LncRNA SLCO4A1-AS1 facilitates growth and metastasis of colorectal cancer through beta-catenindependent Wnt pathway. J Exp Clin Cancer Res CR. 2018;37(1):222.

72. Zhang M, Weng W, Zhang Q, Wu Y, Ni S, Tan C, Xu M, Sun H, Liu C, Wei $P$, et al. The IncRNA NEAT1 activates Wnt/beta-catenin signaling and promotes colorectal cancer progression via interacting with DDX5. J Hematol Oncol. 2018;11(1):113.

73. Lv SY, Shan TD, Pan XT, Tian ZB, Liu XS, Liu FG, Sun XG, Xue HG, Li XH, Han $Y$, et al. The IncRNA ZEB1-AS1 sponges miR-181a-5p to promote colorectal cancer cell proliferation by regulating Wnt/beta-catenin signaling. Cell Cycle (Georgetown, Tex). 2018;17(10):1245-54.

74. Chen L, Gao H, Liang J, Qiao J, Duan J, Shi H, Zhen T, Li H, Zhang F, Zhu Z, et al. miR-203a-3p promotes colorectal cancer proliferation and migration by targeting PDE4D. Am J Cancer Res. 2018;8(12):2387-401.

75. Gugnoni M, Ciarrocchi A. Long noncoding RNA and epithelial mesenchymal transition in cancer. Int J Mol Sci. 2019;20(8):1924.

76. Shan Z, An N, Qin J, Yang J, Sun H, Yang W. Long non-coding RNA Linc00675 suppresses cell proliferation and metastasis in colorectal cancer via acting on miR-942 and Wnt/ $\beta$-catenin signaling. Biomed Pharmacother. 2018;101:769-76.

\section{Publisher's Note}

Springer Nature remains neutral with regard to jurisdictional claims in published maps and institutional affiliations. 